\title{
Epstein-Barr virus and post-transplant lymphoproliferative disease
}

Holmes RD, Sokol RJ. Epstein-Barr virus and post-transplant lymphoproliferative disease.

Pediatr Transplantation 2002: 6: 456-464. (C) 2002 Blackwell Munksgaard

Abstract: There is convincing evidence that Epstein-Barr virus (EBV) is associated with post-transplant lymphoproliferative disease (PTLD). Primary EBV infection following transplantation occurs in as many as $90 \%$ of cases of PTLD in children and pretransplant EBV seronegativity is a recognized risk factor for developing PTLD. Other risk factors include young age at the time of transplant, the type of transplant that the recipient receives and the type and intensity of immunosuppression. The clinical presentation is often nonspecific and tissue biopsy is necessary to establish the diagnosis. There appears to be a correlation between PTLD and EBV viral load measured by polymerase chain reaction (PCR) of the peripheral blood and quantitative PCR may be a useful guide in the management of PTLD. Antiviral drugs and cytomegalovirus-immunoglobulin $\mathrm{G}$ may have a role in preventing PTLD. Because PTLD results from functional over-immunosuppression, the initial treatment is reduction of immunosuppression. Antiviral agents, interferon, immuno-based monoclonal therapy, cell-based therapy and chemotherapy also have a potential role in treating this disorder. At the present time there is no standardized approach to the evaluation and treatment of PTLD.

\author{
R. D. Holmes ${ }^{1}$ and R. J. Sokol ${ }^{2}$ \\ ${ }^{1}$ Department of Pediatrics, University of Michigan, \\ Ann Arbor, Michigan, USA ${ }^{2}$ Pediatric Liver Center and \\ Liver Transplantation Program, Department of \\ Pediatrics, University of Colorado Health Sciences
}

Center and the Children's Hospital, Denver, Colorado, USA

Key words: EBV - post-transplant lymphoproliferative disease - transplantation

R. D. Holmes, MD, Department of Pediatrics, University of Michigan Medical School, D3252 MPB, 1500 E. Medical Center Drive, Ann Arbor, Ml 481090718, USA

Tel.: 734-7639650

Fax: 734-7637359

E-mail: rdholmes@umich.edu

Accepted for publication 26 June 2002
Post-transplant lymphoproliferative disease (PTLD) does not refer to a single disease but to a family of closely related disorders. These disorders are typically associated with uncontrolled proliferation of B cells or (in some cases) $\mathrm{T}$ cells or null cells of both $\mathrm{T}$ - and B-cell origin. The reported incidence of PTLD in pediatric patients following solid-organ transplant varies

\footnotetext{
Abbreviations: CD, cluster of differentiation; CMV, cytomegalovirus; CsA, cyclosporin A; CT, computerized tomography; CTL, cytotoxic T lymphocyte; EA, early antigen; EBER, EBV-encoded RNA; EBNA, Epstein-Barr nuclear antigen; EBV, Epstein-Barr virus; IgG, immunoglobulin G; IgM, immunoglobulin M; IL, interleukin; IFN$\alpha$, interferon- $\alpha$; LCH, Langerhans' cell histiocytosis; LMP, latent membrane protein; LP, leader protein (EBNA leader protein); MHC, major histocompatibility complex; NHL, non-Hodgkin's lymphoma; NK, natural killer; OKT3, murine monoclonal antibody orthoclone; PBL, peripheral blood lymphocytes; PCR, polymerase chain reaction; PTLD, post-transplant lymphoproliferative disease; QC, quantitative competitive; RT-PCR, reverse transcriptionpolymerase chain reaction; Th, helper $\mathrm{T}$ cell; VCA, viral capsid antigen.
}

according to the organ transplanted: combined liver-kidney transplant up to $33 \%$; heart transplant $15 \%$; liver transplant $10 \%$; lung transplant $6.4 \%$; and kidney transplant $1.2 \%(1-3)$. The type of transplant may also influence the outcome of patients who develop PTLD. Mortality from PTLD in pediatric kidney transplant patients has been reported to be as high as $48 \%$, in liver transplants $44 \%$, in thoracic organ transplants (heart/lung and lung) $36 \%$, and in heart transplants $25 \%$ (2). In addition, PTLD following heart transplant appears to be more aggressive and to carry an increased probability of progressing into NHL (4). The greatest risk of PTLD is in children who acquire primary EBV infection following transplantation and in those who are treated with OKT3 for steroid-resistant allograft rejection $(5,6)$. The highest mortality in all types of solid-organ transplants occurs in children who develop PTLD within the first 6 months following transplant (2).

The evidence that EBV is associated with PTLD is convincing. Children with PTLD have a higher incidence of primary or reactivated EBV infection 
as compared with the general transplant population (93\% vs. 30\%) (7). A high level of EBV DNA in the blood of solid-organ transplant recipients has been shown to predict PTLD, and the EBV genome can be detected in tumors from patients with PTLD $(8,9)$. Most cases of PTLD that occur during the first year following solid-organ transplantation (early onset) are associated with recent EBV infection. Late-developing (late-onset) lymphomas, occurring after the first year, are less likely to be associated with EBV infection and usually fall into the subtype of NHL (10).

This review will focus on the risk imposed on immunosuppressed, transplanted children for PTLD caused by EBV infection and discuss an approach for evaluating and treating this potentially life-threatening disorder. Although the child who has had liver transplantation will be emphasized, the concepts are pertinent to children who have received other solid-organ transplants.

\section{Epstein-Barr virus}

EBV infection

EBV is a DNA virus that infects B cells. EBV infection typically begins in the oropharyngeal epithelium. The first step in virus-cell interaction involves attachment of the major envelope glycoprotein, gp350, of the virus with the CD21 molecule on the membrane of the B cell (11). As the oropharyngeal (replicative) EBV infection resolves, an inactive state (latency) follows, with EBV present in small numbers of B cells (12). EBV induces and controls B-cell proliferation in a process referred to as immortalization, and results in an increase in the number of infected cells prior to virus production and cell lysis (13). After receiving an appropriate stimulus, production of virions resumes in a process called reactivation.

Virus-driven lymphoproliferation of B cells is characterized by the expression of at least eight viral genes. These include six nuclear proteins (EBNA-1, -2, -3A, -3B, -3C and -LP) and two latent membrane proteins (LMP-1, -2). In addition, two non-translated, small ribonucleic acids (EBER-1 and-2) can be identified in infected cells (13). One of the membrane proteins (LMP-1) specifically induces the expression of several Blymphocyte activation antigens and has potent growth-altering effects on a wide variety of cells, acting as an oncogene. LMP-1 is a transforming protein that induces a signaling response in $\mathrm{B}$ cells that mimics the CD40 surface molecule, resulting in up-regulation of cellular adhesion molecules, cytokine production and B-cell proliferation (14). LMP-1-expressing cells are also protected from apoptosis (15). These factors play a role in the pathogenesis of EBV-associated diseases and PTLD.

Cellular immune responses are the critical component in the control of EBV infection. Early control of the proliferation of B cells results from NK-cell activity. Two of the latent proteins, EBNA-2 and LMP-1, have been identified as target antigens for EBV-specific CTLs directed against proliferating B cells, and it is these CTLs that subsequently check uncontrolled B-cell production $(16,17)$. CTLs directed against the EBVlytic proteins (BZLF1, BMLF1, BRLF1, BCRF1, BMRF1, BHRF1) are capable of eliminating cells in which viral replication has been initiated and are important in preventing viral spread (18). However, the virus is never completely eradicated and remains in a small number of latently infected B cells for the rest of the person's life (13).

\section{Identifying EBV infections}

\section{Antibody responses to EBV antigens}

Infection with EBV initially results in the production of EBNA followed by expression of EA. Production of late gene products, including the complex of viral structural proteins collectively termed 'VCA', occurs next. Appearance of the EBV antigens results in a predictable pattern of antibody production in the immunocompetent child. Anti-VCA IgM appears first and is soon followed by production of anti-EA and anti-VCA IgG. Levels of anti-EA and anti-VCA IgM decline within a few months. Anti-VCA IgG remains detectable for life.

In acute infection in an immunocompetent host, anti-VCA IgG and anti-VCA IgM are usually detected. Anti-EA may or may not be present. In patients who have had a recent infection, antiVCA IgG remains positive, while anti-VCA-IgM, anti-EA and anti-EBNA may or may not be found. Anti-VCA IgG and anti-EBNA are found in patients who have had a remote infection. In immunocompetent children previously infected with EBV, the reappearance of anti-VCA IgM, increased anti-VCA IgG or increasing anti-EA titers may be used as criteria to identify reinfection. The presence of anti-EBNA excludes acute infection. EBV serology may be misleading in immunosuppressed children. Following acute infection in patients previously EBV seronegative, EBV-specific IgM and IgG antibodies may only appear in very low titer or not at all. In addition, children who were EBV seropositive prior to transplantation may develop high EBV antibody titers as a result of immunosuppression (19). The anti-EBNA response is compromised in immunosuppressed patients, and absent or significantly 
decreased anti-EBNA titers may be associated with PTLD (20).

\section{PCR to identify the EBV viral load}

Several studies have shown a correlation between EBV viral load in the peripheral blood, as measured by PCR, with PTLD $(21,22)$. Utilizing the technique of semi-quantitative or quantitative PCR, EBV viral loads of $\geq 40$ genomes $/ 10^{5}$ PBL in children who were EBV naïve prior to transplant and of $\geq 200$ genome $/ 10^{5} \mathrm{PBL}$ in children infected prior to transplant, are considered to be consistent with an increased risk of PTLD (23). However, these threshold values have not been confirmed in other series and additional studies need to be carried out. In the absence of the use of anti-B-cell antibody, a decrease in the EBV viral load below 200 copies/ $10^{5} \mathrm{PBL}$ is suggestive of the development of EBV-specific immunity and implies a clinical response to treatment (24). Viral load may also be reported as copies $/ 10^{7} \mathrm{~B}$ cells, copies $/ 10^{6}$ PBLs, copies $/ \mu \mathrm{g}$ of DNA, and copies $/ \mathrm{mL}$ of blood. Rowe et al. have calculated conversion values for each assay, comparing the values to copies $/ 10^{5}$ PBLs (Table 1) (25).

Techniques for continuous real-time PCR monitoring have recently been developed (26, 27). Using this technique, Witte et al. (28) have identified a complex pattern of transient elevation of PCR followed by a rapid decline in EBV copy numbers following EBV infection. They confirmed that rising numbers correlate with the onset of clinical EBV disease and decline following treatment of PTLD (28). Serial real-time measurements may be a powerful tool for adjusting the immunosuppression level in response to EBV genome load.

\section{$R T-P C R$ to characterize EBV gene expression} EBV infection of $B$ lymphocytes results in a characteristic pattern of expression of viral genes that can be identified by RT-PCR of the peripheral blood. There are three patterns of gene

Table 1. Conversion of measurements of Epstein-Barr viral load

\begin{tabular}{lccc}
\hline Units & $\begin{array}{l}\text { Conversion } \\
\text { factor }\end{array}$ & Low load & High load \\
\hline Copies $/ 10^{5} \mathrm{PBL}$ & 1 & $8-200$ & $>200$ \\
Copies $/ \mu \mathrm{g} \mathrm{DNA}$ & 3 & $24-600$ & $>600$ \\
Copies $/ 10^{6} \mathrm{PBL}$ & 10 & $80-2000$ & $>2000$ \\
Copies $/ \mathrm{mL}$ of blood & 20 & $160-4000$ & $>4000$ \\
$\left(\approx 2 \times 10^{6} \mathrm{PBL}\right)$ & 1000 & $10^{4}-10^{5}$ & $>10^{5}$ \\
Copies $/ 10^{7} \mathrm{PBL}$ & & & \\
\hline
\end{tabular}

PBL, peripheral blood lymphocytes.

Reprinted with permission from Rowe et al. Transpl Infect Dis 2001: 3: 79-87 (25). expression distinguishable in the immunocompetent host (29). In the latent or resting state the mRNA for LMP2a is consistently detected. The six viral genes (EBNA1, EBNAA2, EBNA3A, EBNA3C, EBNALP and LMP1) that are directly implicated in the process of immortalization may be detected in the immortalized or proliferating state. The third pattern, the virusproducing (or lytic) state, is characterized by the expression of $>60$ early and capsid genes. In immunosuppressed hosts, there are two distinct patterns of gene expression which relate to the EBV viral load of the host. Infected patients in whom the EBV viral load is $\leq 100$ genomes $/ 10^{5}$ PBL have a pattern indistinguishable from the latency pattern in healthy persons. When the viral load is > 200 genomes $/ 10^{5}$ PBL, LMP2a and LMP1 are persistently detectable and accompanied by sporadic detection of EBNA1 and EBNA2 (29). There is a heterogeneous pattern of gene expression in patients with PTLD (30). However, patients with EBV viral loads of $>200$ genomes $/ 10^{5} \mathrm{PBL}$, and with persistent or intermittent expression of EBNA2 in the peripheral blood, may be at increased risk of developing PTLD (29).

\section{PTLD}

Risk factors for developing PTLD

Several risk factors for developing PTLD have been identified. As much as $90 \%$ of PTLD is triggered by a primary EBV infection occurring in the first 3-4 months after transplant, making pretransplant seronegativity a risk factor for the development of PTLD (5). The type of transplant that the recipient receives has also been recognized as a risk factor for developing PTLD. Recipients of heart, liver, lung, and intestine allografts are at greater risk of PTLD than patients who receive a renal allograft (1). As primary EBV infection occurs mainly in young solid-organ transplant patients, age at the time of transplant is a risk factor (31). The type and intensity of immunosuppression are recognized risk factors. When first introduced, CsA was associated with an increased risk for developing PTLD (32). When tacrolimus became available it was initially associated with a 6-10-fold increase in the incidence of PTLD (33). However, recent data suggest a similar risk of developing PTLD when either agent is used, i.e. $4.3 \%$ vs. $6.6 \%$, respectively (34). This may be a reflection of learning to adjust the doses of these agents and how to use them in combination with other immunosuppressives. Only pan-lymphocytic antibodies such as OKT3 significantly increase the 
risk of PTLD (35). Infection with CMV is also a risk factor and is independent of the intensity of immunosuppression. Children who are CMV seronegative at time of transplant and receive a liver from a CMV-seropositive donor are at greatest risk (36).

Children with LCH have an increased risk for developing PTLD after liver transplantation (37). It is not clear why LCH results in an increased incidence of PTLD. LCH has been reported to be associated with malignant neoplasms in nontransplant patients (38). It is possible that previous chemotherapy in transplanted patients with $\mathrm{LCH}$-associated neoplasms may contribute to the cumulative immunosuppressive effect and the risk of PTLD. LCH cells also produce proinflammatory cytokines that may predispose to the development of PTLD (37).

\section{Clinical presentation}

The clinical symptoms of PTLD are often nonspecific. Affected children may present with fever and malaise or with an infectious mononucleosislike syndrome accompanied by palpable lymphadenopathy. Anorexia, weight loss and diarrhea (with or without heme-positive stools) lasting for longer than 14 days should raise the index of suspicion. However, up to $85 \%$ of patients $<1 \mathrm{yr}$ of age may be symptom-free at the time of the first virologic evidence of EBV infection (39). PTLD may be confused with rejection or infection and is often associated with the presence of opportunistic infections.

PTLD can involve nearly any organ system and may present as disseminated disease or with focal organ involvement, including unilateral tonsillar enlargement. The disease may affect any solid or hollow organ, with consequent dysfunction of that organ. The distribution of PTLD may be abdominal (64\%), thoracic (50\%), head and neck (25\%), and brain (6\%) (39). Children with abdominal PTLD may present with hepatomegaly, splenomegaly or other palpable abdominal mass. The gastrointestinal tract is a common site of involvement. In some patients, symptoms of PTLD are limited to the gastrointestinal tract, resulting in anemia $(100 \%)$, gastrointestinal bleeding $(100 \%)$, weight loss $(89 \%)$, fevers $(89 \%)$, hypoalbuminemia $(89 \%)$, anorexia $(78 \%)$, chronic diarrhea $(67 \%)$, and abdominal pain (44\%) (40). Involvement of the allograft is not uncommon, being reported in $80 \%$ of lung transplants, $33 \%$ of liver transplants, and $32 \%$ of kidney transplants (14). The disease may be rapidly progressive or it may wax and wane for several weeks.
Diagnosis

Tissue biopsy is necessary to establish the diagnosis of PTLD. Excised lymph nodes diagnostic of PTLD usually show complete architectural effacement and contain B cells in all stages of maturation (41). The major histologic classification for PTLD was described by Nalesnik et al. who defined three categories: polymorphic; monomorphic; and minimal polymorphism. The polymorphic pattern consists of a diffuse population of small lymphocytes and large cleaved and non-cleaved cells, plasmacytoid cells, plasma cells and immunoblasts. The monomorphic category is much less common and is composed of uniform lymphoid cells at one stage of differentiation. Typically, these cells are either small or large, non-cleaved lymphocytes characteristic of NHL (41). NHL characterized by the finding of small noncleaved cells, phenotypically B cells, is referred to as Burkitt's lymphoma, while tumors consisting of large non-cleaved cells may be B cell, $\mathrm{T}$ cell or indeterminate (42). The T-cell infiltrate may represent an attempt at host immune control of the B-cell proliferation (4). The presence of EBV within PTLD lesions may be confirmed by in situ hybridization using an EBER probe (9).

During the first post-transplant year the clinical diagnosis is based often upon documenting the presence of EBV infection and B-cell proliferation. The laboratory findings used to identify EBV infection in immunocompetent persons (atypical lymphocytosis, VCA-IgM, and heterophile antibodies) may or may not be present in immunosuppressed children. The absence or loss of anti-EBNA may precede EBV/PTLD, and the lack of seroconversion following primary EBV infection may be a risk factor for mortality from EBV/PTLD (2, 43).

When PTLD is suspected, PCR for EBV should be performed on PBL. If the EBV level is elevated, an intensive diagnostic evaluation should proceed, including CT scan of the chest, abdomen and pelvis. Head CT should be performed if the child exhibits neurological symptoms. Children with tonsillar hypertrophy should undergo tonsillectomy and the tissue submitted for histopathologic examination (44). PTLD may be seen in tonsillar tissue even when EBV PCR is inconclusive (45). Lymph node biopsies should be performed on all patients with clinically significant peripheral lymphadenopathy. Laparoscopic biopsy of intra-abdominal lymph nodes or masses may be necessary. Gastrointestinal endoscopy and biopsy should be performed on 
all patients with chronic diarrhea or proteinlosing enteropathy.

\section{Prophylaxis to prevent EBV infection from progressing to PTLD}

Antiviral treatment

Antiviral agents may have a role in preventing PTLD. Acyclovir and ganciclovir both demonstrate in vitro activity against the linear (replicating) form of EBV but not the cyclic (latent) form (46). Ganciclovir also limits the transformation of lymphocytes by EBV (47). Although data from controlled randomized trials suggest little benefit of antiviral prophylaxis in decreasing the incidence of PTLD, several non-randomized studies show potential benefit (48-50). For antiviral prophylaxis to have any significant impact on EBV-induced PTLD, the agent should be present at or before the time of transmission of EBV from the donor to the recipient. Antiviral prophylaxis during, and for 3 months after, administration of anti-lymphocyte antibody may decrease the incidence of PTLD (50).

Immunoglobulin

Anecdotal reports suggest that the occurrence of PTLD is lower in transplant recipients who receive CMV-IgG as a component of their therapy (51). The significant immune dysregulation resulting from CMV infection may play a role in the development of PTLD. CMV replication is associated with increased production of cytokines potentially capable of reactivating EBV infection and capable of altering the number and function of circulating $\mathrm{T}$ cells (52). Additional mechanisms of immunomodulation by CMV, such as transactivation of EBV genes, are theoretically possible $(53,54)$. However, the overall role of immunoglobulin therapy and the impact of giving antibody to EBV, contained in nearly equal amounts in intravenous immunoglobulin preparations or hyper-IgG products such as CMV-IgG, is uncertain (Personal Communication, MedImmune, Inc., Gaithersburg, MD, USA). Although some centers use immunoglobulin therapy to prevent PTLD, there are no conclusive data to support this practice.

\section{Treatment of PTLD}

Reduction of immunosuppression therapy

As PTLD results from functional over-immunosuppression, the initial treatment in all patients is a reduction in immunosuppression. Regression of PTLD following reduction of prednisone doses and stopping all other immunosuppressives has been reported to occur in $23-50 \%$ of patients $(55,56)$. However, it is not certain whether immunosuppression should be stopped or reduced in all patients, as reducing doses of immunosuppressants may result in allograft rejection. In some cases, PTLD may present with clinical or histologic evidence which are so suggestive of malignancy, Burkett's-type lymphoma or NHL that a trial of reduced immunosuppression may not be warranted.

\section{Antiviral treatment}

The role of antiviral therapy in treating PTLD is unclear. As many as $90 \%$ of EBV-infected cells in PTLD are transformed B cells that do not undergo lytic replication (57). Neither acyclovir nor ganciclovir are effective in vitro against latently infected B cells (58). However, it is theoretically possible that ganciclovir will prevent the $5-10 \%$ of affected $\mathrm{B}$ cells undergoing lytic replication from producing new virus which could infect new B-cell clones (57). Although one report describes a patient in whom the activity of PTLD appeared to correlate with starting and stopping treatment with acyclovir, the efficacy of acyclovir or ganciclovir in comparative clinical trials has not been established $(59,60)$.

\section{Interferon}

IFN- $\alpha$ is a cytokine that increases the lytic potential of NK cells, inhibits viral replication and increases expression of class I MHC molecules. IFN- $\alpha$ also promotes an environment which enhances production of cytokines that mediate delayed-type hypersensitivity and allow CTLs and NK cells to thrive. There have been no randomized trials of IFN- $\alpha$ for treatment of PTLD in liver transplant patients. However, there are case reports describing successful treatment $(61,62)$. In one published series, IFN- $\alpha$ was used following reduction of immunosuppression. There was a complete response to therapy in $50 \%$ of patients treated for longer than 3 weeks (63). IFN- $\alpha$ can be given without the risk of infection associated with traditional chemotherapy; however, there may be an increased risk of rejection in patients treated with IFN- $\alpha$ (64).

Immuno-based monoclonal therapy

Anti-B-cell antibody trials, using chimeric mouse/human monoclonal antibody against the CD20 B-cell antigen, have been reported in the treatment of PTLD (65). Preliminary results, from a multi-center phase II study testing the 
response rate and durability of treatment with this antibody, suggest that anti-CD20 may have an important role in the management of PTLD (66). In a recent report, anti-CD20 was administered to six patients with progressive disseminated PTLD or bulky lesions, and treatment resulted in a decreased EBV load and disappearance of tumor masses (67). In another series, the 1 -yr survival after anti-CD20 therapy was no more than $50 \%$, owing to treatment-related toxicity and infection (68). The indications for using this agent are not yet defined. A tumor-lysis syndrome may occur following administration of anti-CD20, and immunoglobulin synthesis may be suppressed for a number of months (69).

\section{Cell-based therapy}

As reduction in the number of EBV-specific CTLs allows the outgrowth of EBV-transformed B cells, resulting in PTLD, restoration of CTLs may lead to regression of PTLD. Treatment employing adoptive-cell therapy, where donor-derived EBV-specific CTLs are used to restore CTLs in bone marrow-transplant recipients, has been used successfully against EBV/PTLD (70, 71) Applying this technology to the treatment of PTLD in solidorgan transplant recipients has remained a significant challenge. However, Khanna et al. have developed a protocol for activating autologous EBV-specific CTL lines from immunosuppressed solid-organ recipients who acquired their EBV infection after engraftment (72). Their results demonstrated that EBV-specific T cells may have therapeutic potential in recipients of solid-organ transplants.

\section{Chemotherapy}

Chemotherapy is a treatment option when PTLD has not been responsive to other therapies or if the patient presents with a Burkitt-like or Hodgkin-like tumor (73). Complete remissions have been reported using multi-drug chemotherapy (traditionally used to treat NHL), with as many as $70 \%$ of patients achieving a disease-free interval for 19 months (74). Remissions have been achieved using a low-dose chemotherapy regimen of cyclophosphamide $\left(600 \mathrm{mg} / \mathrm{m}^{2}\right)$ for 1 day and prednisone $(2 \mathrm{mg} / \mathrm{kg} /$ day $)$ for 5 days administered every 3 weeks for six cycles (75). Other treatment regimens using cyclophosphamide, doxorubicin, vincristine and prednisone for Burkitt-like lymphoma, or LH 89 for Hodgkinlike PTLD, have been well tolerated and successful (73). Chemotherapy and withdrawal of immunosuppression may be successfully used without graft rejection.

\section{Other treatments}

Surgical resection and radiotherapy for anatomically limited disease should be considered. Special treatment of central nervous system PTLD may be necessary, including systemic and intrathecal chemotherapy or intrathecal infusion of B-cell monoclonal antibody (76). These interventions should be accompanied by a reduction in immunosuppression.

\section{Approach to prevention and treatment}

Several approaches have been developed in an attempt to modify primary EBV infection or EBV reactivation following transplantation. One approach is to monitor relative EBV viral loads at 3-12-month intervals post-transplantation by EBV DNA PCR in order to assess the risk for developing PTLD, and to make modifications in therapy to reduce this risk (8). When threshold values for EBV DNA PCR of $\geq 40$ and $\geq 200$ genomes $/ 10^{5} \mathrm{PBL}$ are exceeded for pretransplant seronegative and pretransplant seropositive patients, respectively, it has been suggested that immunosuppression should be reduced, and ganciclovir and/or CMV-IgG be initiated if PCR values do not respond (49). Although the initial therapeutic intervention in all symptomatic patients should be reduction of immunosuppression, it is not known just how much reduction is required, of which agents, and for how long this reduction needs to be instituted. Treatment is continued until the EBV PCR levels fall below these threshold values. However, it is controversial whether all patients who reach these threshold EBV DNA values require therapeutic changes that may place them at risk for precipitating an episode of allograft rejection. The relative amount of immunosuppression at the time of the EBV primary infection or reactivation, the patient's history of rejection episodes, and other host variables must be taken into account before reducing immunosuppression based solely on PCR values. Treatment with other agents, including chemotherapy, must be considered when the viral load does not decrease following these interventions and certainly if PTLD develops. This approach is outlined in Fig. 1.

\section{Conclusions}

The natural history of PTLD is extremely variable and specific prognostic indicators are not 


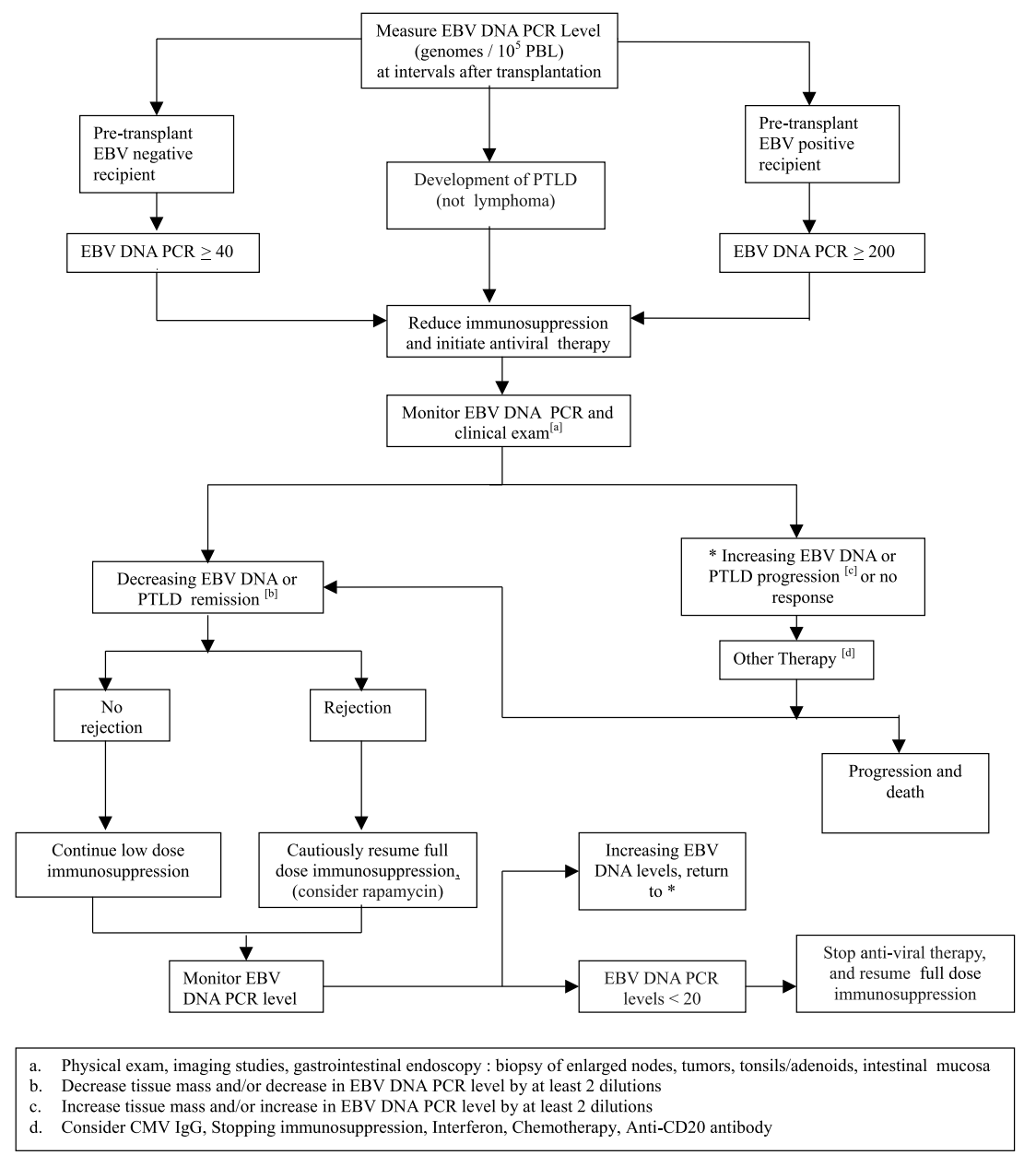

Fig. 1. Suggested algorithm for management of elevated Epstein-Barr virus (EBV) DNA levels and post-transplant lymphoproliferative disease (PTLD).

well established. There are no definitive data regarding the overall survival rate for children who develop PTLD following liver transplantation. The clinical setting in which PTLD occurs appears to be important in determining the outcome. The survival rate may depend upon the time of onset of PTLD following transplantation. Generally, early-onset PTLD has a better outcome than late-onset disease (77). Death is not always caused by PTLD, but may occur as a result of sepsis. Groups reported with the highest mortality rate are patients with disseminated disease and systemic symptoms (78). The poor prognosis of the patients with disseminated disease may relate to delays in diagnosis and continued or increased immunosuppression. Patients with a better prognosis include those with a mononucleosis-like illness, a lymphadenopathic presentation and single-organ involvement. Although mortality is high in patients with disseminated disease and those who do not initially respond to reduction of immunosuppression, multi-drug chemotherapy regimens have been successful in inducing and sustaining remission (75). At the present time there is no standardized approach to the evaluation and treatment of PTLD following liver or other solid-organ transplant. The only manner in which a standard approach will be developed is through prospective, multi-centered investigation.

\section{References}

1. Dror Y, Greenberg M, Taylor G, Superina R, et al. Lymphoproliferative disorders after organ transplantation in children. Transplantation 1999: 67: 990-998.

2. Collins MH, Montone KT, Leahey RL, et al. Post-transplant lymphoproliferative disease in children. Pediatr Transpl 2001: 5: 250-257.

3. Aris RM, Maia DM, Neuringer IP, et al. Post-transplantation lymphoproliferative disorder in the Epstein-Barr virus naïve lung transplant recipient. Am J Respir Crit Care Med 1996: 154: 1712-1717.

4. Kowal-Vern A, Swinner L, Pyle J, et al. Characterization of postcardiac transplant lymphomas. Histology, immunophenotyping, immunohistochemistry, and gene rearrangement. Arch Pathol Lab Med 1996: 120: 41-48.

5. Ho M, Jaffe R, Miller G, Breinig MK, et al. The frequency of Epstein-Barr virus infection and associated lymphoproliferative syndrome after transplantation, and its manifestations in children. Transplantation 1988: 45: 719-727.

6. McDiarmid SV, Wallace P, Vargas J, et al. The treatment of intractable rejection with tacrolimus (FK506) in pediatric liver transplant recipients. J Pediatr Gastroenterol Nutr 1995: 20: 291-299. 
7. Ho M, JAFFe R, Miller G, et al. The frequency of EpsteinBarr virus infection and associated lymphoproliferative syndrome after transplantation and its manifestations in children. Transplantation 1988: 45: 719-727.

8. Baldanti F, Grossi P, Furione M, et al. High levels of Epstein-Barr virus DNA in blood of solid-organ transplant recipients and their value in predicting posttransplant lymphoproliferative disorders. J Clin Microbiol 2000: 38: 613-619.

9. Randhawa PS, Jaffee R, Demetris AJ, et al. Expression of Epstein-Barr virus-encoded small RNA (by the EBER-1 gene) in liver specimens from transplant recipients with post-transplantation lymphoproliferative disease N Eng J Med 1992: 327: $1710-1714$.

10. Harris NL, Jaffe ES, Stein H, et al. A revised EuropeanAmerican classification of lymphoid neoplasm: A proposal from the international lymphoma study group. Blood 1994: 84: 1361-1392.

11. Fingeroth JD, Weiss JJ, Telder TF, et al. Epstein-Barr virus receptor of human B lymphocytes is the C3d receptor CR2. Proc Natl Acad Sci USA 1984: 81: 4510-4514.

12. Yao QY, Rowe M, Martin B, et al. The Epstein-Barr virus carrier state: Dominance of a single growth-transforming isolate in the blood and in the oropharynx of healthy virus carriers. J Gen Virol 1991: 72: 1579-1590.

13. Rowe DT. Epstein-Barr virus immortalization and latency. Front Biosci 1999: 4: D346-D371.

14. Cohen JL. Epstein-Barr virus infection. N Engl J Med 2000: 343: 481-492.

15. Fries K, Miller W, Raab-Traub N. Epstein-Barr virus latent membrane protein 1 blocks p53-mediated apoptosis through the induction of the A20 gene. J Virol 1996: 70: 8653-8659.

16. Kerr BM, Lear AL, Rowe M, et al. Three transcriptionally distinct forms of Epstein-Barr virus latency in somatic cell hybrids: Cell phenotype dependence of virus promoter usage. Virology 1992: 187: 189-201.

17. Haque T, Amlot Pl, Helling N, et al. Reconstitution of EBV-specific $\mathrm{T}$ cell immunity in solid organ transplant recipients. J Immunol 1998: 160: 6204-6209.

18. Ibish C, Saulquin X, Gallot $G$, et al. The $T$ cell receptoire selected in vitro against EBV. Diversity, specificity, and improved purification through early IL-2 receptor $\alpha$-chain (CD25)-positive selection. J Immunol 2000: 1674: 4924-4932.

19. Hopwood P, Crawford DH. The role of EBV in post-transplant malignancies: A review. J Clin Pathol 2000: 53: 248-254.

20. Cen H, Williams HP, McWilliams MC, et al. Evidence for restricted Epstein-Barr virus latent gene expression and antiEBNA antibody response in solid organ transplant recipients with posttransplant lymphoproliferative disorders. Blood 1993: 81: 1393-1403

21. Kenagy DH, Schleisinger Y, Weck K, et al. Epstein-Barr virus DNA in peripheral blood leukocytes of patients with posttransplant lymphoproliferative disease. Transplantation 1995: 60: 547-554.

22. Rooney CM, Loftin SK, Holladay MS, et al. Early identification of Epstein-Barr virus-associated post-transplantation lymphoproliferative disease. Br J Haematol 1995: 89: 98-103.

23. Green M, Cacciarelli TV, Mazariegos GV, et al. Serial measurement of Epstein-Barr viral load in peripheral blood in pediatric liver transplant recipients during treatment for posttransplant lymphoproliferative disease. Transplantation 1998: 66: 1641-1644.

24. Rowe DT, Qu L, Reyes J, et al. Use of quantitative competitive PCR to measure Epstein-Barr virus genome load in the peripheral blood of pediatric transplant patients with lymphoproliferative disorders. J Clin Microbiol 1997: 35: 16121615.

25. Rowe DT, Webber S, Schauer EM, et al. Epstein-Barr virus load monitoring: Its role in the prevention and management of post-transplant lymphoproliferative disease. Transpl Infect Dis 2001: 3: 79-87.

26. Orit T, Оhконсhi N, Koyamada $\mathrm{N}$, et al. Usefulness of quantitative real-time polymerase chain reaction with EpsteinBarr virus infection after liver transplantation. Clin Transpl 2000: 14: 308-317.
27. Kimura H, Morita M, Yabuta Y, et al. Quantitative analysis of Epstein-Barr virus load by using real-time PCR assay. J Clin Microbiol 1999: 37: 132-136.

28. Witte D, Groen P, Bucuvalas J, et al. New method for determination of EBV viral load in transplant recipients. Am J Transplant 2001: S1: 204.

29. Qu L, Green M, Webber S, et al. Epstein-Barr virus gene expression in the peripheral blood of transplant recipients with persistent circulating viral loads. J Infect Dis 2000: 182: 1001311021.

30. Rowe D, Niedobitek G, Young L. EBV gene expression in posttransplant lymphoproliferative disorders. Springer Semin Immunopathol 1998: 20: 389-403.

31. Cox KL, Lawrence-Miyasaki LS, Garcia-Kennedy R, et al. An increased incidence of Epstein-Barr virus infection and lymphoproliferative disorder in young children on FK506 after liver transplantation. Transplantation 1995: 59: 524-529.

32. Starzl TE, Nalesnik M, Porter KA, et al. Reversibility of lymphomas and lymphoproliferative lesions developing under cyclosporin-steroid therapy. Lancet 1984: 1: 583-587.

33. Reding R, Wallemace PE, Lamy ME, et al. Conversion from cyclosporine to FK506 for salvage of immunocompromised pediatric liver allografts. Efficacy, toxicity, and dose regimen in 23 children. Transplantation 1994: 57: 93-100.

34. Shapiro R, Nalesnik M, McCauly J, et al. Posttransplant lymphoproliferative disorders in adult and pediatric renal transplant patients receiving tacrolimus-based immunosuppression. Transplantation 1999: 68: 1851-1854.

35. Swinnen LJ, Costanzo-Nordin MR, Fisher SG, et al. Increased incidence of lymphoproliferative disorder after immunosuppression with the monoclonal antibody OKT3 in cardiactransplant recipients. N Eng J Med 1990: 323: 1723-1728.

36. Manez R, Breinig MC, Linden P, et al. Posttransplant lymphoproliferative disease in primary Epstein-Barr virus infection after liver transplantation: The role of cytomegalovirus disease. J Infect Dis 1997: 176: 1462-1467.

37. Newell KA, Alonso EM, Kelly SM, et al. Association between liver transplantation for Langerhans cell histiocytosis, rejection, and development of posttransplant lymphoproliferative disease in children. J Pediatr 1997: 131: 98-104.

38. Egeler RM, Neglia JP, Puccetti DM, et al. Association of Langerhans' cell histiocytosis with malignant neoplasms. Cancer 1993: 71: 865-873.

39. Pickhardt PJ, Siegel MJ, Hayashi RJ, Kelly M. Posttransplantation lymphoproliferative disorder in children: Clinical, histopathologic, and imaging features. Radiology 2000: 217: 16-25.

40. Younes BS, Ament M, McDiarmid SV, et al. The involvement of the gastrointestinal tract in posttransplant lymphoproliferative disease in pediatric liver transplantation. J Pediatr Gastroenterol Nutr 1999: 28: 380-385.

41. Nalesnik MA, Jaffee R, Starzl TE, et al. The pathology of posttransplant lymphoproliferative disorders occurring in the setting of cyclosporine A-prednisone immunosuppression. Am J Pathol 1988: 133: 173-192.

42. SAndlund JT, Downing JR, CRist WM. Non-Hodgkin's lymphoma in childhood. N Engl J Med 1996: 334: 1238-1248.

43. Riddler SA, Breining MC, MCKnight JLC. Increased levels of circulating Epstein-Barr virus infected lymphocytes and decreased EBV nuclear antigen antibody responses are associated with the development of posttransplant lymphoproliferative disease in solid organ transplant recipients. Blood 1994: 84: 972-984.

44. Broughton S, McClay Je, Murray A, et al. The effectiveness of tonsillectomy in diagnosing lymphoproliferative disease in pediatric patients after liver transplantation. Arch Otolaryngol Head Neck Surg 2000: 126: 1444-1447.

45. Lones MA, Mishalani S, Shintaku IP, et al. Changes in tonsils and adenoids in children with posttransplant lymphoproliferative disorder: Report of cases with early involvement of Waldeyer's ring. Hum Pathol 1995: 26: 525-530.

46. Lin JC, Smith MC, Pagano JS. Prolonged inhibitory effect of 9-(1,3-dihydroxy-2-propoxymethyl) guanine against replication of Epstein-Barr virus. J Virol 1984: 50: 50-55. 
47. Crumpacker CS. Ganciclovir. N Engl J Med 1996: 335: 721 729.

48. Yao QY, Ogan P, Rowe M, et al. Epstein-Barr virus-infected $B$ cells persist in the circulation of acyclovir-treated virus carriers. Int J Cancer 1989: 43: 67-71.

49. Green M, Kaufman M, Wilson J, Ryes J. Comparison of intravenous ganciclovir followed by oral acyclovir with intravenous ganciclovir alone for prevention of cytomegalovus and Epstein-Barr virus disease after liver transplantation in children. Clin Infect Dis 1997: 25: 1344-1349.

50. Davis CL, Harrison KL, MCVICAR JP, et al. Antiviral prophylaxis and the Epstein-Barr virus-related post-transplant lymphoproliferative disorder. Clin Transpl 1995: 9: 53-59.

51. Hart GD, Paya CV. Prophylaxis for CMV should now replace pre-emptive therapy in solid organ transplantation. Rev Med Virol 2001: 11: 73-81.

52. Manez R, Brenig MC, Linden P, et al. Posttransplant lymphoproliferative disease in primary Epstein-Barr virus infection after liver transplantation: the role of cytomegalovirus disease. J Infect Dis 1997: 176: 1462-1467.

53. Rinaldo CR. Immune suppression by herpesviruses. Annu Rev Med 1990: 41: 331-338.

54. Graczyk MJ, Paraskevas S, Gruessner RWG, Coad JE. Post-transplant lymphoma after abdominal organ transplantation: An association with cytomegalovirus. Am J Transplant 2001: S1: 402.

55. Penn I. The role of immunosuppression in lymphoma formation. Springer Semin Immunopathol 1998: 20: 343-355.

56. Benkerrow M, Durandy A, Fischer A. Therapy for transplant-related lymphoproliferative diseases. Hematol Oncol Clin North Am 1993: 7: 467-475.

57. DAVIS CL. The antiviral prophylaxis of post-transplant lymphoproliferative disorder. Semin Immunopathol 1998: 20: 437-453.

58. Lin JC, Sмith MC, Pagano JS. Prolonged inhibitory effect of 9-(1,3-dihydroxy-2-propoxymethyl) guanine against replication of Epstein-Barr virus. J Virol 1984: 50: 50-55.

59. Hanto DW, Fizzera G, Gajl-Peczalska KJ, et al. Acyclovir therapy of Epstein-Barr virus-induced posttransplant lymphoproliferative diseases. Transplant Proc 1985: 17: 89-92.

60. Paya CV, Fung JJ, Nalesnik MA, et al. Epstein-Barr virus induces post transplant lymphoproliferative disorders. Transplantation 1999: 68: 1517-1525.

61. Kane Re, Bunchman TE, Vogler C, Brems JJ. Treatment of a B-cell lymphoproliferative disorder in a liver transplant patient with interferon alfa and gamma globulin: a case report. Clin Transpl 1992: 6: 164-168.

62. O'Brien S, BERNERT RA, Logon Ji, Lien YHH. Remission of posttransplant lymphoproliferative disorder after interferon alpha therapy. J Am Soc Nephrol 1997: 8: 1483-1490.

63. Davis CL, Wood BL, Sabath DE, et al. Interferon- $\alpha$ treatment of posttransplant lymphoproliferative disorder in recipients of solid organ transplants. Transplantation 1998: 66: 1770-1779.

64. Green M, Michaels MG, Webber SA, et al. The management of Epstein-Barr associated post-transplant lymphoproliferative disorder in pediatric solid-organ transplant recipients. Pediatr Transpl 1999: 3: 271-281.
65. Milpied N, Vasseur B, Parquet N, et al. Humanized antiCD20 monoclonal antibody (Rituximab) in post transplant Blymphoproliferative disorder: A retrospective analysis on 32 patients. Ann Oncol 2000: 1: 113-116.

66. Webber SA, Fine RN, McGhee WM, et al. Anti-CD20 monoclonal antibody (Rituximab) for pediatric post-transplant lymphoproliferative disorders: a prelimary multicenter experience. Am J Transplant 2001: S1: 469.

67. Serinet M, Jacquemin E, Habes D, et al. Anti-CD20 monoclonal antibody (Rituximab) treatment for Epstein-Barr virusassociated, B-cell lymphoproliferative disease in pediatric liver transplant recipients. J Pediatr Gastroenterol Nutr 2002: 34: 389-393.

68. Fischer A, Blanche S, Lebidois J, et al. Anti-B-cell monoclonal antibodies in the treatment of severe B-cell lymphoproliferative syndrome following bone marrow and organ transplantation. N Engl J Med 1991: 324: 1451-1456.

69. Gross TG. Treatment of Epstein-Barr virus-associated posttransplant lymphoproliferative disorders. J Pediatr Hematol Oncol 2001: 23: 7-9.

70. Heslop He, Brenner MK, Rooney CM. Donor T cells to treat EBV-associated lymphoma. N Engl J Med 1994: 331: $679-680$.

71. Heslop He, Brenner MK, Rooney CM, et al. Clinical protocol: Administration of neomycin resistant gene marked EBV specific CTL to recipients of mismatched-related or phenotypically similar unrelated donor marrow grafts. Hum Gene Ther 1994: 5: 381-397.

72. Khanna R, Bell S, Sherritt M, et al. Activation and adoptive transfer of Epstein-Barr virus-specific cytotoxic $\mathrm{T}$ cells in solid organ transplant patients with posttransplant lymphoproliferative disease. Proc Natl Acad Sci USA 1999: 96: 10391-10396.

73. Smets F, Vajro P, Cornu G, et al. Indications and results of chemotherapy in children with posttransplant lymphoproliferative disease after liver transplantation. Transplantation 2001: 69: 9982-9984.

74. Hayashi RJ, Kraus MD, Patel Al, et al. Posttransplant lymphoproliferative disease in children; correlation of histology to clinical behavior. J Pediatr Hematol Oncol 2001: 23: 14-18.

75. Gross TG, Hinrichs SH, Winner J, et al. Treatment of posttransplant lymphoproliferative disease (PTLD) following solid organ transplantation with low-dose chemotherapy. Ann Oncol 1998: 9: 339-340.

76. Stephan JL, Le Deist F, Blanche S, et al. Treatment of central nervous system B lymphoproliferative disease by local infusion of a B cell specific monoclonal antibody. Transplantation 1992: 54: 246-249.

77. Dotтi G, Fiocchi R, Mотто T, et al. Epstein-Barr virus negative lymphoproliferative disorders in long term survivors of heart, kidney and liver transplant. Transplantation 2000: 69: 827-833.

78. Hanto DW, Gajl-Peczalska KJ, Fizzera G, et al. EpsteinBarr virus (EBV) induced polyclonal and monoclonal B-cell lymphoproliferative diseases occurring after renal transplantation. Clinical, pathologic, and virologic findings and implications for therapy Ann Surg 1983: 198: 356-369. 